\title{
PERSISTENT TRUNCUS ARTERIOSUS
}

BY

\section{ROBERT MARSHALL}

From the Royal Victoria Hospital, Belfast

Received August 1, 1943

A boy of thirteen years was first seen at his own home on April 5, 1943. A congenital heart lesion had been diagnosed early in life: he was undersized, but showed no other congenital defect; and there was cyanosis and clubbing of fingers. He was alert, intelligent, and engaging. For three days he had been vomiting blood in small quantities, but the total loss had been considerable. When first examined his heart rate was 144 a minute, the rhythm regular, and the pulse volume very poor. The apex beat was diffusely felt in the fifth space about two and a half inches from the mid-sternum; there was no thrill; there were soft systolic and diastolic murmurs audible all over the præcordium, but these murmurs proved to be transient.

On admission to hospital the hæmatemesis ceased, his pulse rate fell to normal, and no murmur could as a rule be heard, though sometimes there was an apical systolic bruit. Congenital methæmoglobinæmia as a contributory cause for his cyanosis was excluded. His blood pressure was usually 120/70. On April 19, his red cell count was 7,500,000 and his hæmoglobin 130 per cent. His temperature was unstable with a maximum of $100^{\circ} \mathrm{F}$. Hæmatemesis recurred but never in alarming amounts. On April 28, his cyanosis was more intense, and gallop rhythm was present with a heart rate of 108 , but this disappeared before his death from congestive failure on May 13.

The electrocardiogram showed large P waves in leads I and II; the S waves were approximately twice the amplitude of the $\mathrm{R}$ waves in leads I and III with splintering of QRS in II (Fig. 1).

An X-ray picture of the chest by portable apparatus showed " an enlarged globular heart of congenital type" (Fig. 2).
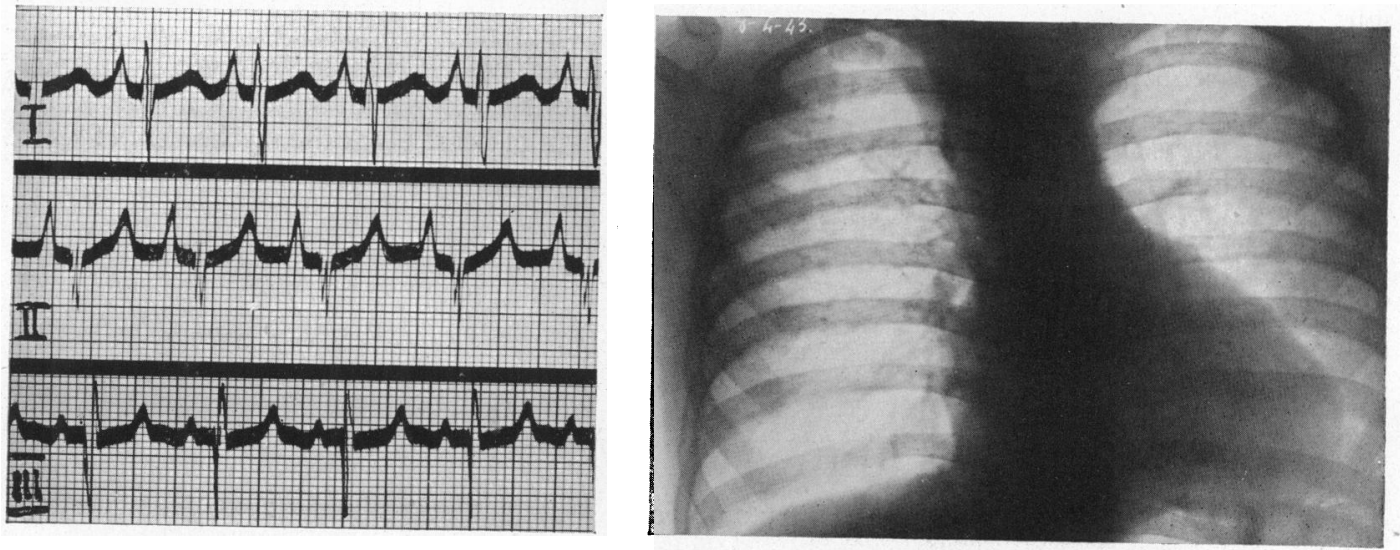

FIG. 1 and 2.-Electrocardiogram and radiogram (see text). 
The transient murmurs made clinical diagnosis of the nature of his malformation difficult. The hæmatemesis was correctly attributed to œsophageal varices.

\section{NECROPSY REPORT}

The heart was rather bulbous in shape. The longitudinal and transverse measurements being about the same-three and a half inches.

The transverse enlargement was entirely in the right ventricle, which completely covered the left ventricle when the heart was viewed from the front. The right auricle was very large and passed upwards and forwards in front of the aorta. The aorta was normal in appearance for its first one and a half inches and was only very slightly displaced to the right. There was no pulmonary artery arising from the right ventricle; instead a large arterial trunk arose from the left side of the aorta about one and a half inches from its origin (Fig. 3). This pulmonary trunk divided into a right and left artery after a course of about one and a half inches. The superior and inferior venæ cavæ emptied into the right auricle and the pulmonary veins emptied normally into the left auricle which was very small. The major branches of the aorta arose in their usual sites from the aortic arch.

The epicardium was normal and the sub-epicardial fat was considerable in amount. The veins in it were rather prominent.

On dividing the heart in its long axis through auricle and ventricle, the right auricle was found to be dilated and there was a large patent foramen ovale. The myocardium was hypertrophied, and the musculi pectinati were enormously hypertrophied. The auricular appendage between the musculi pectinati was very thin and almost transparent. The tricuspid valve was normal. The muscle of the right ventricle was hypertrophied and measured $2 \mathrm{~cm}$. in thickness. The ventricular septum was slightly thicker. There was a complete absence of the membranous septum and the conus arteriosus was absent (Fig. 4). The blood must have passed through the deficient membranous septum to the aorta. The left auricle was very small and the myocardium was not hypertrophied. The mitral valve was normal and the left ventricular wall was slightly thicker than normal. The aorta opened from this

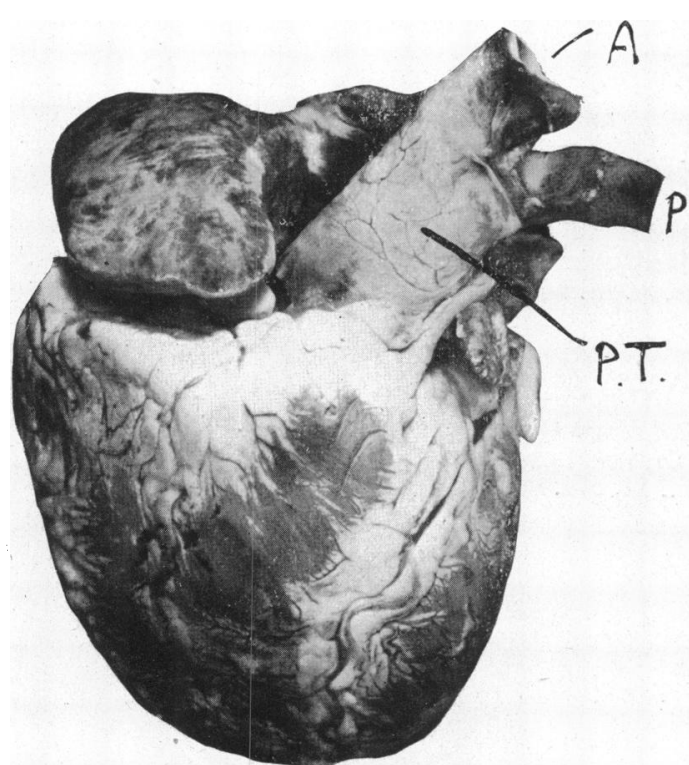

FIG. 3.-Anterior aspect of the heart showing enlarged right auricle and ventricle. P.T.= persistent truncus arteriosus. $\mathbf{A}=$ aorta. $\mathbf{P}=$ pulmonary artery.

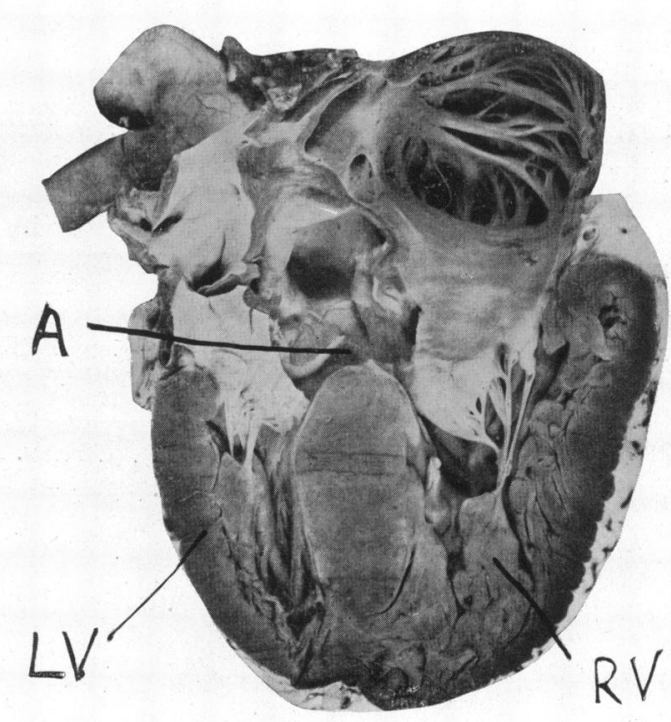

Fig. 4.-The heart on section, showing the absence of the pars membranacea of the interventricular septum. 
ventricle and apparently the blood which reached it from the right ventricle did so through the deficient septum rather than because of dextroposition of the aorta. The aortic valve was tricuspid and competent; the cusps did not present a "fleshy" appearance and all the heart valves were free from endocarditis.

\section{COMMENT}

Of 1000 cases of congenital cardiac malformation analyzed by Maude Abbott (1932), 21 showed persistent truncus arteriosus; the oldest subject lived to twenty-five, but the average age at death was four years; hypertrophy of the right ventricle was found in 15 and of the left ventricle in 11 cases; dextroposition of the aorta was found in 19 cases. In the case now described it was at first thought that there was no dextroposition but on closer scrutiny it was considered that the truncus was slightly superimposed on the right ventricle and not altogether on the left. Brown (1939) agrees with Humphreys (1932) in describing five types:

(1) Partial common trunk with ductus arteriosus.

(2) Partial common trunk without ductus arteriosus.

(3) Complete common trunk with independent origin of pulmonary arteries.

(4) Complete common trunk with one pulmonary artery and a bronchial artery.

(5) Complete common trunk with no sixth arch derivatives and bronchial arteries.

The present case appears to be of Humphreys' fourth type, the single pulmonary artery arising as a branch from the common trunk and then dividing into right and left branches. Maude Abbott stated that four valve cusps of "fleshy" type are to be expected on embryological grounds but that tricuspid valves have been described in a number of cases including two of her own series. Brown quotes Ross (1935) that the cusps differ from normal cusps by the absence of elastic tissue and their general structure of myomatous tissue, and this finding was confirmed by Abbott. In the present case the three cusps were normal to both naked eye and microscopic examination.

\section{SUMMARY}

A persistent truncus arteriosus was found after death in a boy aged thirteen years, who had always been cyanosed and breathless, and had suffered from hæmatemesis due to œsophageal varices. The cardiac murmurs had been transient; there was no endocarditis and death was attributed to congestive failure. Electrocardiogram, radiogram, and postmortem findings are recorded.

I wish to thank Professor J. H. Biggart for his valued opinion, Dr. C. R. Murdock for the necropsy report, Dr. F. C. Montgomery for the radiogram and Mr. A. M. Mahaffy for photographs of the heart.

\section{REFERENCES}

Abbott, M. E. (1936). Atlas of Congenital Heart Disease, New York, p. 60. Brown, J. W. (1939). Congenital Heart Disease, London, p. 181. Humphreys, E. M. (1932). Archiv. Path., 14, 671. 